\title{
Cognitive outcomes and health-related quality of life in adults two decades after the arterial switch operation for transposition of the great arteries
}

David Kalfa, MD, PhD, ${ }^{\text {a }}$ Leila Kasmi, PhD, MS, ${ }^{\mathrm{b}}$ Nikoletta Geronikola, MS, ${ }^{\mathrm{b}}$ Johanna Calderon, PhD, MS, Virginie Lambert, MD, PhD, ${ }^{\mathrm{d}, \mathrm{e}}$ Emre Belli, MD, ${ }^{\mathrm{e}} \mathrm{f}$ Damien Bonnet, $\mathrm{MD}, \mathrm{PhD},{ }^{\mathrm{g}}$ and Michèle Montreuil, PhD, MS

\section{ABSTRACT}

Objective: The study objective was to evaluate the cognitive and psychosocial outcomes of young adults who underwent an arterial switch operation for transposition of the great arteries.

Methods: Sixty-seven adults with transposition of the great arteries (aged $22.9 \pm 3.3$ years) and 43 healthy subjects matched in age, gender, and educational level participated. Global cognitive functioning, psychologic state, and healthrelated quality of life were evaluated using validated tools. We analyzed patient-related and procedure-related risk factors associated with cognitive and psychosocial outcomes.

Results: Some $69 \%$ of patients had an intelligence quotient greater than 85 (normal range, 85-115). Mean full-scale, verbal, and performance intelligence quotients were lower in patients $(94.9 \pm 15.3,96.8 \pm 16.2,93.7 \pm 14.6$, respectively) than in healthy subjects $(103.4 \pm 12.3, P=.003 ; 102.5 \pm 11.5$, $P=.033 ; 103.8 \pm 14.3, P<.001$, respectively). Cognitive difficulties (intelligence quotient $\leq-1$ standard deviation) and impairments (intelligence quotient $\leq-2$ standard deviations) were more frequent in patients than in the general population $(31 \%$ vs $16 \%, P=.001 ; 6 \%$ vs $2 \%, P=.030)$. Patients with cognitive difficulties had lower educational level $(P<.001)$ and more grade retention at school $(P=.007)$. Patients reported an overall satisfactory health-related quality of life; however, those with cognitive or psychologic difficulties reported poorer quality of life. Predictors of worse outcomes included lower parental socioeconomic and educational status, older age at surgery, and longer hospitalization stay.

Conclusions: Despite satisfactory outcomes in most adults with transposition of the great arteries, a substantial proportion has cognitive or psychologic difficulties that may reduce their academic success and quality of life. Further studies are needed to better understand the long-term outcome of this population to provide prevention,

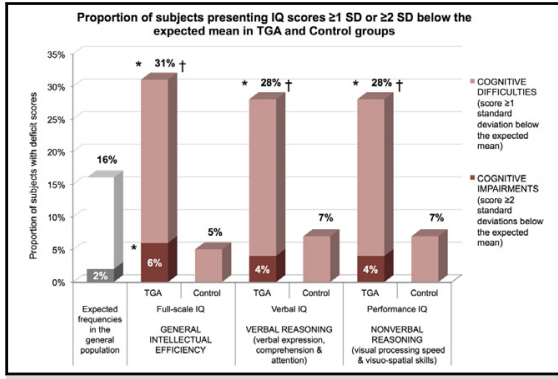

Significant difference between the *TGA group and the general population, and the $†$ TGA group and control group.

\section{Central Message}

Adults with TGA have an increased risk of cognitive disorders likely to reduce their academic success and quality of life.

\section{Perspective}

Our study provides an original description of the cognitive and psychosocial outcomes of adults 2 decades after a neonatal ASO for TGA. This is an essential step to develop prevention strategies and adapted treatments, such as cognitive remediation or psychologic support, for patients who would need it.

See Editorial Commentary page 1036.

See Editorial page 1026. surveillance, and care strategies. (J Thorac Cardiovasc Surg 2017;154:1028-35)

\footnotetext{
From the a Department of Pediatric and Congenital Cardiac Surgery, Morgan Stanley Children's Hospital of New York-Presbyterian, Columbia University Medical Center, New York, NY; 'bepartment of Psychology, Laboratoire de Psychopathologie et Neuropsychologie EA2027, Université Paris 8-Paris Lumières-CNRS, Saint-Denis, France; ${ }^{\mathrm{c}}$ Department of Psychiatry, Harvard Medical School, Boston, Mass; ${ }^{\mathrm{d}}$ Pediatric Department, Hôpital Universitaire Bicêtre, Le Kremlin Bicêtre, France; ${ }^{~}$ Department of Congenital and Pediatric Cardiac Surgery, Centre Chirurgical Marie Lannelongue, Le Plessis-Robinson, France; ${ }^{\mathrm{f}}$ Department of Pediatric Cardiology, Institut Jacques Cartier, Massy, France; and ${ }^{\mathrm{g}}$ Department of Congenital and Pediatric Cardiology, Centre de Référence Malformations Cardiaques Congénitales Complexes (M3C), Hôpital Universitaire Necker-Enfants Malades, Assistance Publique-Hôpitaux de Paris, Université Paris Descartes, Sorbonne Paris Cité, Paris, France.
}

D.K. and L.K. are co-first authors and equal contributors.

Institutional Review Board approval on July 10, 2013; research project $n^{\circ} 13-027$; ID RCB n ${ }^{\circ}$ 2013-A00754-41.

Read at the 96th Annual Meeting of The American Association for Thoracic Surgery, Baltimore, Maryland, May 14-18, 2016.

Received for publication May 25, 2016; revisions received Feb 13, 2017; accepted for publication March 16, 2017; available ahead of print May 2, 2017.

Address for reprints: Leila Kasmi, PhD, MS, Laboratoire de Psychopathologie et Neuropsychologie, Université Paris 8, 2 rue de la Liberté, 93526 Saint-Denis, France (E-mail: leila.kasmi4@gmail.com).

$0022-5223 / \$ 36.00$

Copyright (C) 2017 by The American Association for Thoracic Surgery

http://dx.doi.org/10.1016/j.jtcvs.2017.03.119 


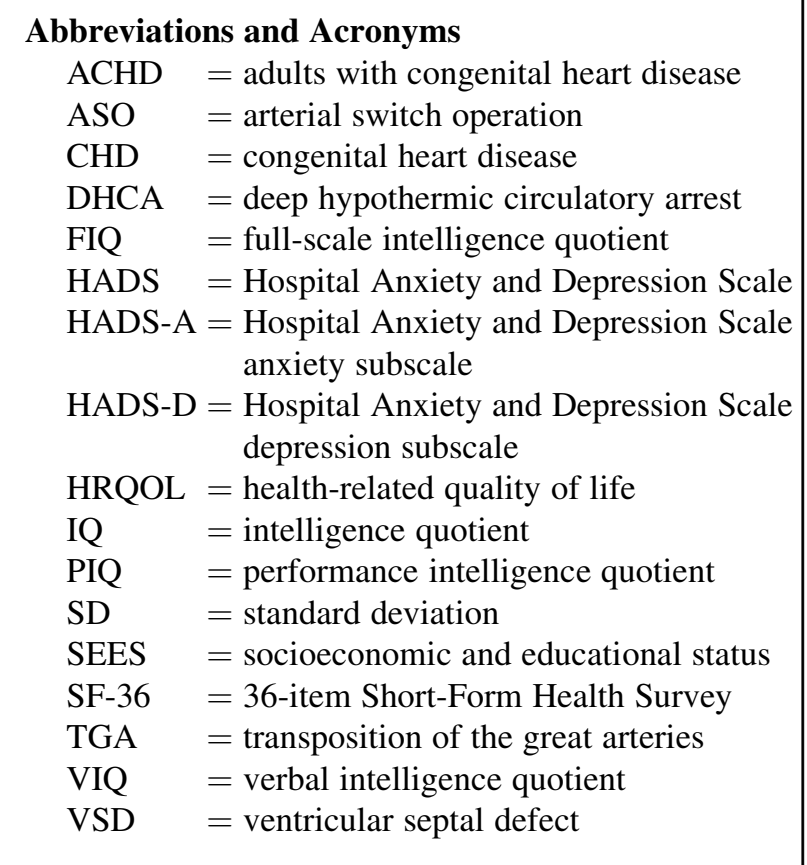

Scanning this QR code will take you to a supplemental video for the article.

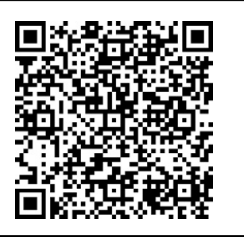

With the dramatic improvement in medical and surgical care of complex congenital heart disease (CHD), attention shifted from mortality and cardiac morbidity to long-term neuropsychologic and psychosocial outcomes. Studies showed that children and adolescents with CHD are at increased risk of neurodevelopmental and psychologic disorders, which may be related to biological and environmental factors. ${ }^{1}$ Since the advent of neonatal repair of complex cardiac lesions, approximately $85 \%$ of patients survive into adulthood, giving rise to a new large patient population called "adults with congenital heart disease" 2 (ACHD). However, few studies have evaluated the cognitive and psychosocial outcomes of adults with complex $\mathrm{CHD}^{3,4}$ The evaluation of the outcomes of young ACHDs seems particularly important because this developmental period is characterized by brain, cognitive, and behavioral changes that could determine social and professional adaptation. Indeed, early adulthood is the time when the last stages of brain development, particularly of prefrontal structures, occur. This crucial phase, marked by new academic, financial, and familial challenges, is a time of high vulnerability during which some psychiatric disorders manifest. ${ }^{5}$
The main objective of this study was to evaluate the cognitive and psychosocial outcomes of young adults who underwent a neonatal arterial switch operation (ASO) to correct transposition of the great arteries (TGA). We also explored the association among cognitive and psychologic difficulties, health-related quality of life (HRQOL), and academic course. Our last objective was to identify potential clinical and sociodemographic risk factors associated with the cognitive and psychologic outcomes of patients.

\section{MATERIALS AND METHODS Participants}

Adults (aged $\geq 18$ years) born with TGA between 1984 and 1995 were identified by reviewing the medical databases of 2 hospitals: Necker Children's Hospital and Marie Lannelongue Hospital, Ile-de-France. Inclusion criteria were a diagnosis of TGA, with intact ventricular septum or ventricular septal defect (VSD), corrected by ASO before 2 months of age (Video 1). Exclusion criteria were a diagnosis of TGA with hypoplastic aortic arch or left ventricular outflow tract obstruction, birth weight less than $2.5 \mathrm{~kg}$, known genetic anomalies, associated severe extracardiac anomalies, severe sensory impairments (eg, vision or hearing), a history of neurologic lesion (eg, traumatic brain injury, brain tumor), and primary language other than French.

The group of patients was compared with a control group of healthy adults, matched on age, gender, and educational level and recruited from the same geographic location (Ile-de-France). We recruited control individuals from diverse social and educational environments (universities, training centers, hospital's employees, and by asking patients' close friends). This study was approved by the Institutional Review Board of Paris-Sud University Medical Center. Written informed consent was obtained from all participants.

\section{MATERIALS}

Participants underwent a comprehensive 2-hour cognitive and psychosocial evaluation based on validated scales administered in a fixed order. Intellectual ability was assessed by a trained neuropsychologist (L.K.) using the Wechsler Adult Intelligence Scale, Third Edition, ${ }^{6}$ the most commonly used standardized scale to measure intelligence quotient (IQ) in adults. It provides scores for verbal IQ (VIQ: verbal reasoning and comprehension), performance IQ (PIQ: processing speed and visual-motor proficiency), and full-scale IQ (FIQ: general intellectual efficiency). These subscales provide normative scores by age with a mean of 100 and a standard deviation (SD) of 15. Cognitive difficulties were measured by scores $1 \mathrm{SD}$ or more below the expected mean (ie, $\leq 85$ ), whereas scores $2 \mathrm{SD}$ or more below the expected mean (ie, $\leq 70$ ) expressed cognitive impairments. The incidence of IQ scores 85 or less or 70 or less in the general population is $16 \%$ or $2 \%$, respectively. ${ }^{6}$

Participants also completed the Hospital Anxiety and Depression Scale (HADS) in the French version ${ }^{8}$ and the 36-item Short-Form Health Survey ${ }^{9}$ (SF-36) in the French version, ${ }^{10}$ which both have an acceptable internal consistency. The HADS assesses the presence and the severity of current depression and anxiety symptomatology. It is divided into an Anxiety subscale (HADS-A) and a Depression subscale (HADS-D), both containing 7 items. Each item is rated on a scale from 0 to 3 to evaluate semiquantitatively the intensity of current symptoms. For each of the 2 subscales, the range of possible scores varies from 0 to 21 points (with higher scores indicating worse outcomes). A score of 8 to 10 suggests a potential anxiety or depressive disorder. A score of 11 to 21 is indicative of more severe anxiety or depressive disorder.

The SF-36 allows a generic measure of HRQOL across 8 physical and emotional domains. It provides 2 summary scales: physical (Physical Component Summary) and psychosocial HRQOL (Mental Component Summary), both calculated from the 8 subscales using algorithms. ${ }^{11}$ 


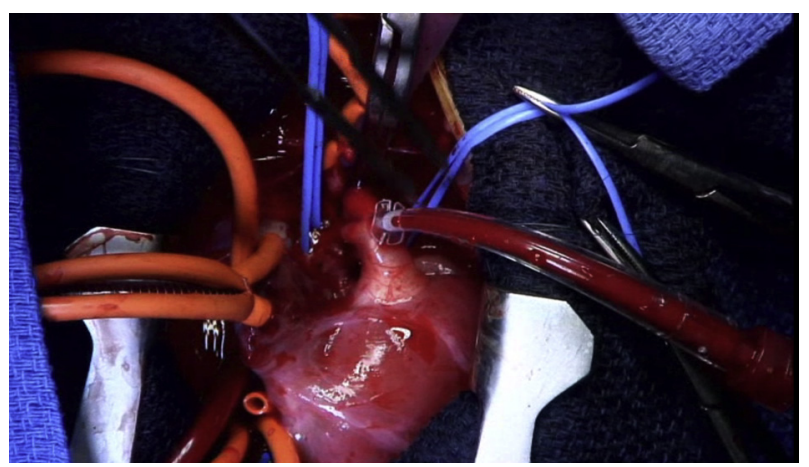

VIDEO 1. Neonatal ASO in a 5-day-old neonate with simple TGA and abnormal coronary anatomy and coronary intramural course. With permission of Dr Belli, Paris, France. Video available at: http://www. jtcvsonline.org/article/S0022-5223(17)30638-4/addons.

They have a mean (SD) of 50 (10), a higher score suggesting a better HRQOL. Finally, we collected preoperative, intraoperative, postoperative, and sociodemographic variables (Table 1).

\section{Statistical Analysis}

Results are expressed as mean \pm SD or percentages. Cognitive and psychosocial outcomes of patients were compared with outcomes of healthy subjects and with normative values of general population, when available. Comparisons between the TGA group and the control group on numeric variables were performed using independent-sample $t$ tests. Standardized scores were compared with normative values from the general population, using 1-sample $t$ tests. Chi-square tests were used for comparisons of categoric variables between groups. Binomial tests were used for comparisons of frequencies observed in the TGA group with those expected in the general population.

In the TGA group, we evaluated the association among cognitive or psychologic difficulties, HRQOL, and academic course. Chi-square tests were used to assess the association between 2 categoric variables, and independent-sample $t$ tests were used to assess the association between categoric and numeric variables.

Finally, we used linear regression analyses to identify risk factors for cognitive and psychosocial outcomes in adults with TGA among the predictors listed in Table 1 . We performed multiple imputations ${ }^{12}$ using the fully conditional specification method (ie, the Markov Chain Monte Carlo method $)^{13}$ and carried out 5 imputations to replace missing values of independent variables (ie, predictors) when a variable had less than $25 \%$ of missing values. Regression analyses were performed from complete data (or "combined results") corresponding to the mean score between observed data and data obtained from the 5 imputations conducted. Predictors associated with outcomes at a level of $P$ less than .20 were considered for stepwise backward regression. Statistical analysis was performed using the Statistical Package for Social Sciences version 22 (IBM, Bois-Colombes, France).

\section{RESULTS}

Among 154 patients meeting eligibility criteria and living in Ile-de-France, $55(36 \%)$ were unreachable. Of the remaining 99 patients, 16 refused to participate and 16 accepted but never presented for evaluation $(68 \%$ of participation rate). Participants did not differ from nonparticipants on gender $(P=.137)$, birth weight $(P=.730)$, VSD prevalence $(P=.883)$, Rashkind procedure use $(P=.881)$, deep hypothermic circulatory
TABLE 1. Clinical characteristics of the transposition of the great arteries group

\begin{tabular}{|c|c|}
\hline Variables & $\begin{array}{c}\text { Percentage (frequency), } \\
\text { mean } \pm \text { SD }(\mathbf{n}) * \\
\text { or quartiles }(\mathbf{n}) * \\
\end{array}$ \\
\hline \multicolumn{2}{|l|}{ Preoperative } \\
\hline Prenatal diagnosis & $23.7 \%(14 / 59)$ \\
\hline VSD & $34.8 \%(23 / 66)$ \\
\hline Gestational age (wk) & $39.4 \pm 1.5(59)$ \\
\hline C-section delivery & $15.8 \%(9 / 57)$ \\
\hline Birth weight $(\mathrm{kg})$ & $3.3 \pm 0.4(60)$ \\
\hline Head circumference $(\mathrm{cm})$ & $34.3 \pm 1.1(45) \dagger$ \\
\hline Apgar score at $5 \mathrm{~min}$ & $9.5 \pm 0.9(52)$ \\
\hline Rashkind procedure & $66.7 \%(42 / 63)$ \\
\hline \multicolumn{2}{|l|}{ Intraoperative } \\
\hline Age at surgery (d) & $\begin{aligned} \mathrm{Q} 1= & 5, \text { median }=7 \\
& \mathrm{Q} 3=10(66)\end{aligned}$ \\
\hline Duration of aortic clamping time (min) & $76.4 \pm 12.8(63)$ \\
\hline Duration of CPB (min) & $157.3 \pm 35.3(51)$ \\
\hline Use of DHCA $\ddagger$ & $9.5 \%(6 / 63)$ \\
\hline Duration of $\mathrm{DHCA} \ddagger(\mathrm{min})$ & $4.2 \pm 3.6(6)$ \\
\hline \multicolumn{2}{|l|}{ Postoperative } \\
\hline Length of stay in ICU (d) & $8.5 \pm 4.9(61)$ \\
\hline Cerebral seizures during ICU stay & $2.2 \%(1 / 44) \dagger$ \\
\hline Total length of hospitalization (d) & $26.4 \pm 8.1(55)$ \\
\hline \multicolumn{2}{|l|}{ Medical history after ASO } \\
\hline $\begin{array}{l}\text { Delayed psychomotor development } \\
\text { in childhood }\end{array}$ & $10.7 \%(6 / 56)$ \\
\hline Subsequent percutaneous intervention & $6.5 \%(4 / 62)$ \\
\hline Subsequent surgical intervention & $18.8 \%(12 / 64)$ \\
\hline \multicolumn{2}{|l|}{ Sociodemographic and family characteristics } \\
\hline Gender, male & $59.7 \%(40 / 67)$ \\
\hline Age at assessment, y & $22.9 \pm 3.3(67)$ \\
\hline Parental educational level $\S$ & $1.4 \pm 1.0(67)$ \\
\hline Parental socioeconomic status $\|$ & $1.7 \pm 0.8(67)$ \\
\hline
\end{tabular}

$S D$, Standard deviation; $V S D$, ventricular septal defect; $C P B$, cardiopulmonary bypass; $D H C A$, deep hypothermic circulatory arrest; $I C U$, intensive care unit; $A S O$, arterial switch operation. *Clinical data were missing for some patients (overall rate of missing values $=8.9 \%$ ). $†$ Variables with $>25 \%$ of missing values were not considered for regression analysis. †The use of DHCA in both institutions during the study period was limited to the intracardiac part of the procedure (atrial septal defect or VSD closure) and not to the extracardiac part (harvest and reimplantation of the coronary arteries, LeCompte maneuver). §Level of the highest degree reached, from 0 to $3(0=$ no high school diploma; $1=$ high school diploma; $2=$ college undergraduate; $3=$ from college graduate to doctoral degree). ||Socioeconomic status calculated on the basis of the French average income depending on socio-professional category (source: National Institute of Statistics and Economic Studies), from 0 (very low socioeconomic level, long-term unemployment, homemaker) to 3 (high socioeconomic level: executive manager, higher intellectual profession).

arrest (DHCA) use $(P=.392)$, aortic clamp duration $(P=.119)$, or bypass duration $(P=.270)$. Nevertheless, compared with nonparticipants, participants had an earlier mean age at surgery $(9.4 \pm 9.7$ days vs $12.4 \pm 11.3$ days, $P=.018$ ), shorter duration of circulatory arrest $(4.2 \pm 3.6$ minutes vs $29.9 \pm 9.5$ minutes, $P<.001)$, and earlier age at assessment $(22.9 \pm 3.4$ years vs $25.7 \pm 3.1$ years, $P<.001)$. Finally, compared with patients not lost to follow-up but who refused or never presented for 
TABLE 2. Sociodemographic, academic, and professional characteristics by group

\begin{tabular}{|c|c|c|c|}
\hline \multirow[b]{2}{*}{ Variables } & \multicolumn{2}{|c|}{$\begin{array}{c}\text { Groups, percentage } \\
\text { (frequency) or mean } \pm \text { SD }\end{array}$} & \multirow[b]{2}{*}{$\begin{array}{c}P \\
\text { value }\end{array}$} \\
\hline & $\begin{array}{l}\text { TGA group } \\
(\mathrm{n}=67)\end{array}$ & $\begin{array}{c}\text { Control group } \\
(\mathrm{n}=\mathbf{4 3})\end{array}$ & \\
\hline Gender, male & $59.7 \%(40 / 67)$ & $55.8 \%(24 / 43)$ & .687 \\
\hline Age (18-31 y) & $22.9 \pm 3.3$ & $23.8 \pm 2.8$ & .164 \\
\hline \multicolumn{4}{|l|}{ Educational level } \\
\hline No. of years of education* & $13.6 \pm 2.1$ & $14.1 \pm 2$ & .177 \\
\hline Diploma degree $\dagger$ & $1.4 \pm 0.9$ & $1.5 \pm 0.8$ & .414 \\
\hline $\begin{array}{l}\text { Rates of grade retention } \\
\text { at school }\end{array}$ & $56.7 \%(38 / 67)$ & $48.8 \%(21 / 43)$ & .419 \\
\hline $\begin{array}{l}\text { Unemployment rates } \\
\text { among nonstudents }\end{array}$ & $23.3 \%(7 / 30)$ & $14.3 \%(3 / 21)$ & .108 \\
\hline $\begin{array}{c}\text { Socioeconomic status } \\
\text { of nonstudents } \ddagger\end{array}$ & $1.7 \pm 0.7$ & $1.7 \pm 0.8$ & .818 \\
\hline Parental educational level $\dagger$ & $1.4 \pm 1.0$ & $1.4 \pm 1.2$ & .639 \\
\hline$\underline{\text { Parental socioeconomic status } \ddagger}$ & $1.7 \pm 0.8$ & $1.6 \pm 0.7$ & .622 \\
\hline \multicolumn{4}{|c|}{$\begin{array}{l}S D \text {, Standard deviation; } T G A \text {, transposition of the great arteries. *Number of years of } \\
\text { education starting from the first grade of elementary school (12 years of education } \\
\text { corresponding to the high school diploma). } \dagger \text { Level of the highest degree reached, } \\
\text { from } 0 \text { to } 3(0=\text { no high school diploma; } 1=\text { high school diploma; } 2=\text { college } \\
\text { undergraduate; } 3=\text { from college graduate to doctoral degree). } \ddagger \text { Socioeconomic status } \\
\text { calculated on the basis of the French average income depending on socio-professional } \\
\text { category, from } 0 \text { (very low socioeconomic level, long-term unemployment) to } 3 \text { (high } \\
\text { socioeconomic level: executive manager). }\end{array}$} \\
\hline
\end{tabular}

evaluation, participants had a higher educational level (13.6 \pm 2.1 years of education vs $12.3 \pm 1.8$ years of education, $P=.014$ ) for an equivalent age at assessment $(P=.586)$.

A total of 67 adults (aged 18-31 years) who underwent an ASO for TGA were included. The clinical characteristics of the TGA group are presented in Table 1. The control group consisted of 43 healthy subjects matched to the patients in age, gender, and educational level. Sociodemographic data by group are presented in Table 2 .

\section{Cognitive Outcomes}

Mean IQ scores are presented in Table 3. Sixty-nine percent of patients had an FIQ greater than 85 (normal range, 85-115). Mean FIQ and PIQ were significantly lower in patients than the expected population's mean of 100 $(P=.008$ and $P<.001$, respectively). Moreover, mean FIQ, VIQ, and PIQ were significantly lower in patients $(94.9 \pm 15.3,96.8 \pm 16.2$, and $93.7 \pm 14.6$, respectively) compared with healthy subjects $(103.4 \pm 12.3, P=.003$; $102.5 \pm 11.5, P=.033$; and $103.8 \pm 14.3, P<.001$, respectively).

In the TGA group, the frequency of scores $1 \mathrm{SD}$ or greater or $2 \mathrm{SD}$ or greater below the expected mean (ie, $\leq 85$ or $\leq 70$; expected frequency $16 \%$ or $2 \%$ ) was $31 \%$ and $6 \%$ for FIQ, respectively, and $28 \%$ and $4 \%$ for both VIQ and PIQ, respectively (Figure 1). Thus, compared with expected frequencies in the general population, the proportion of
TABLE 3. Cognitive and psychosocial outcomes in adults with operated transposition of the great arteries compared with control group

\begin{tabular}{lccc}
\hline & \multicolumn{2}{c}{ Groups, mean \pm SD } & \\
\cline { 2 - 3 } Variables & TGA $(\mathbf{n}=\mathbf{6 7})$ & Control $(\mathbf{n}=\mathbf{4 3})$ & $\boldsymbol{P}$ value* \\
\hline WAIS-III & & & \\
FIQ & $94.9 \pm 15.3$ & $103.4 \pm 12.3$ & .003 \\
VIQ & $96.8 \pm 16.2$ & $102.5 \pm 11.5$ & .033 \\
PIQ & $93.7 \pm 14.6$ & $103.8 \pm 14.3$ & $<.001$ \\
HADS & & & \\
HADS-D $\dagger$ & $3.2 \pm 2.3$ & $3.4 \pm 2.7$ & .631 \\
HADS-A $\dagger$ & $7.1 \pm 3.7$ & $6.7 \pm 3.7$ & .589 \\
SF-36 & & & \\
PCS & $52.1 \pm 7.5$ & $55.4 \pm 5.9$ & .012 \\
MCS & $47.2 \pm 10.3$ & $44.5 \pm 11.5$ & .201 \\
\hline
\end{tabular}

$S D$, Standard deviation; TGA, transposition of the great arteries; WAIS-III, Wechsler Adult Intelligence Scale, Third Edition; $F I Q$, full-scale intelligence quotient; $V I Q$, verbal intelligence quotient; $P I Q$, performance intelligence quotient; $H A D S$, Hospital Anxiety and Depression Scale; HADS-D, Hospital Anxiety and Depression Scale depression subscale; HADS-A, Hospital Anxiety and Depression Scale anxiety subscale; SF-36, 36-item Short-Form Health Survey; PCS, Physical Component Summary; MCS, Mental Component Summary. $* P$ values are determined by independent samples $t$ tests comparing the TGA group with the control group. $\dagger$ Data from the HADS were missing for 3 patients with TGA.

patients with scores of 85 or less was significantly higher for FIQ $(P=.001)$, VIQ $(P=.005)$, and PIQ $(P=.005)$, whereas the proportion of patients with scores of 70 or less was significantly higher for FIQ only $(P=.030)$.

\section{Psychosocial Outcomes}

Mean scores of depression and anxiety symptomatology are presented in Table 3. Mean scores in HADS-D and in HADS-A were not significantly different between the TGA and control groups. Furthermore, the proportion of patients with possible depression (HADS-D $\geq 8 ; 3.1 \%$ ) or anxiety disorder (HADS-A $\geq 8 ; 39.1 \%$ ) was not different from that of healthy participants $(7 \%, P=.39$ and $34.9 \%, P=.66$, respectively). Finally, the frequency of disorders (HADS-D or HADS-A $\geq 11$ ) was not different between groups: No patient and 1 healthy subject $(2.3 \%)$ showed high depressive symptomatology $(P=.40)$, and $18.8 \%$ of patients versus $18.6 \%$ of healthy subjects presented high anxiety symptomatology $(P=.99)$.

Overall, patients reported satisfying HRQOL, as expressed by mean scores in the physical domain (SF-36 Physical Component Summary) and psychosocial domain (SF-36 Mental Component Summary) falling within the normal range of 40 to 60 (Table 3). Among 67 patients, $61(91 \%)$ had a score greater than 40 (expressing normal or high level of HRQOL) in the physical domain and 53 $(79 \%)$ had a score greater than 40 in the psychosocial domain. However, compared with healthy subjects, patients reported poorer HRQOL in the physical domain (55.4 \pm 5.9 vs $52.1 \pm 7.5$, respectively, $P=.012$ ). 
Proportion of subjects presenting IQ scores $\geq 1$ SD or $\geq 2$ SD below the expected mean in TGA and Control groups

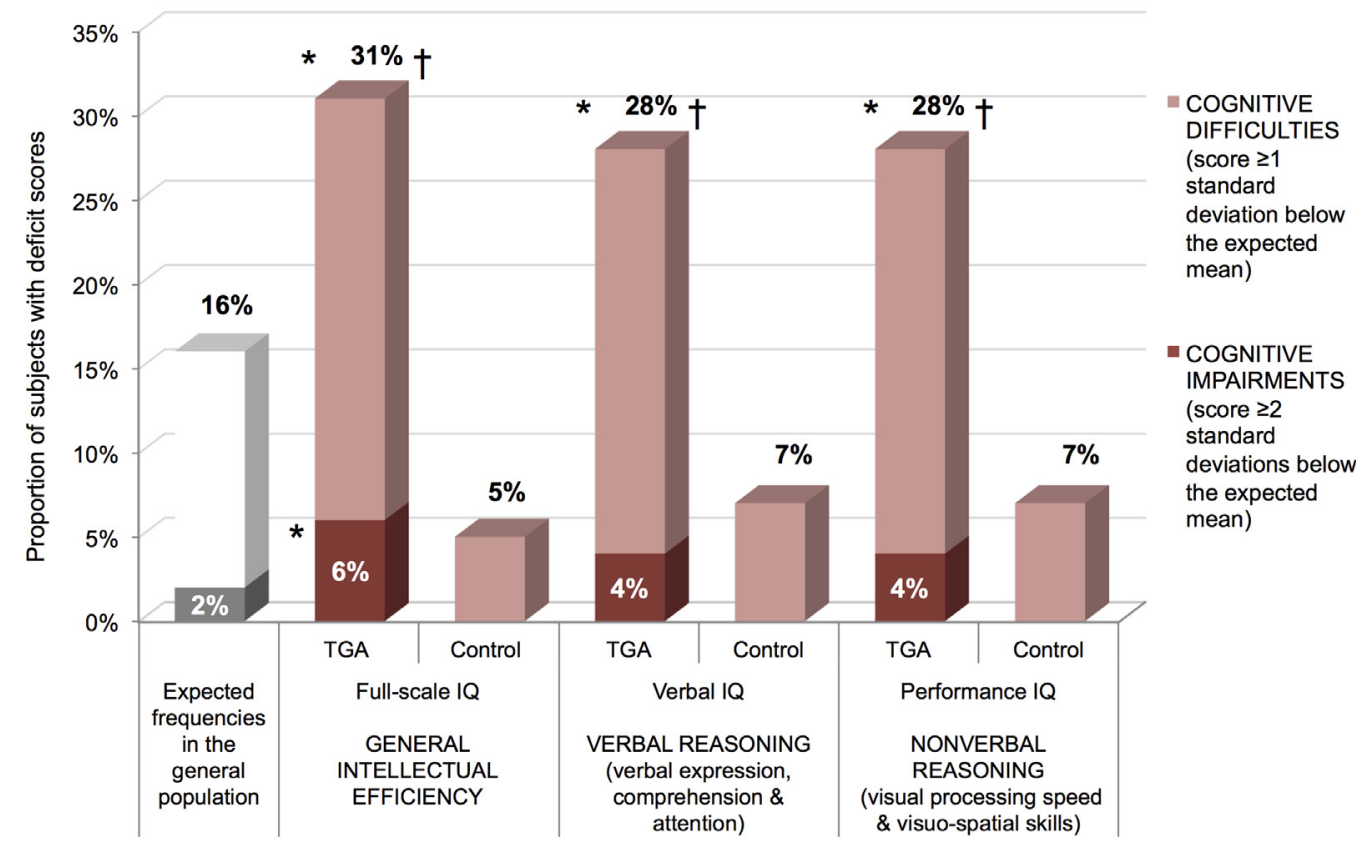

FIGURE 1. *Significant difference between frequencies observed in the TGA group and expected frequencies in the general population. $\nmid$ Significant difference between frequencies observed in the TGA group and those observed in the control group. IQ, Intelligence quotient; $S D$, standard deviation; $T G A$, transposition of the great arteries.

Relations Between Cognitive or Psychologic Difficulties With Health-Related Quality of Life and Academic Course in the Transposition of the Great Arteries Group

Cognitive difficulties (FIQ $\leq 85$ ) and anxiety disorder (HADS-A $\geq 11$ ) were significantly associated with poorer HRQOL. Patients presenting with an FIQ of 85 or less reported lower physical HRQOL (48.8 \pm 7.4$)$ compared with patients with an FIQ greater than 85 (53.6 \pm 7.2 , $P=.013)$. Moreover, patients with HADS-A of 11 or greater reported lower psychosocial HRQOL $(41.1 \pm 9.6)$ compared with patients with HADS-A less than 11 $(48.9 \pm 9.8, P=.015)$.

Finally, cognitive difficulties were associated with lower educational level (years of education: $12.4 \pm 2.2$ vs $14.3 \pm 1.7, P<.001)$ and higher proportion of grade retention at school $(81 \%$ vs $46 \%, P=.007)$.

\section{Multivariate Risk Factors Analysis for Cognitive and Psychosocial Outcomes}

Predictors of cognitive and psychosocial parameters are presented in Table 4. Among predictors associated with outcomes in univariate linear regression analysis, few remained significantly associated with outcomes in multivariate analysis. Risk factors for lower IQ were lower parental socioeconomic and educational status (SEES) and older age at surgery. Predictors of higher anxiety symptomatology were older age at surgery and longer total length of hospitalization. Predictors of higher depressive symptomatology were intact ventricular septum and absence of Rashkind procedure before ASO. Finally, among significant HRQOL predictors in univariate analysis (parental SEES, Apgar score, length of stay in intensive care unit), no variable remained significantly associated with HRQOL in multivariate analysis.

\section{DISCUSSION}

The aims of this study were to evaluate the (1) cognitive and psychosocial outcomes of adults with TGA corrected by ASO, (2) possible impact of cognitive and psychologic difficulties on academic course and HRQOL, and (3) potential risk factors of cognitive or psychologic outcomes.

Our cohort of adults with TGA displayed FIQ and PIQ scores significantly reduced compared with the normal values and the control group's scores. Our findings suggest that the cognitive morbidities commonly reported in children and adolescents with complex $\mathrm{CHD}^{14}$ persist into adulthood in individuals with TGA after the ASO. Of note, the proportion of patients with cognitive difficulties (IQ $\leq 85 ; 31 \%$ ) or cognitive impairments (IQ $\leq 70 ; 8 \%$ ) was significantly higher than the expected frequency in the general population. These results are in line with previous findings in adolescents with cyanotic $\mathrm{CHD}^{15-17}$ 
TABLE 4. Multivariate risk factors analysis in the transposition of the great arteries group

\begin{tabular}{|c|c|c|c|}
\hline \multirow[b]{3}{*}{ Predictors } & \multicolumn{3}{|c|}{ Outcome variables } \\
\hline & $\begin{array}{l}\text { Global cognitive functioning } \\
\text { (FIQ) }\end{array}$ & $\begin{array}{c}\text { Anxiety symptoms } \\
\text { (HADS-A) } \\
\end{array}$ & $\begin{array}{c}\text { Depressive symptoms } \\
\text { (HADS-D) }\end{array}$ \\
\hline & \multicolumn{3}{|c|}{$\beta$ Estimate $\pm \mathrm{SE}(P$ value $)$} \\
\hline Gender & $\mathrm{X}$ & & \\
\hline Parental SEES* & $8.3 \pm 2.0(<.001)$ & $\mathrm{X}$ & \\
\hline Prenatal diagnosis & & $\mathrm{X}$ & \\
\hline VSD & & & $-1.2 \pm 0.6(.048)$ \\
\hline Birth weight & & $\mathrm{X}$ & \\
\hline Rashkind procedure & & & $-1.2 \pm 0.6(.043)$ \\
\hline Age at surgery & $-0.4 \pm 0.2(.015)$ & $0.1 \pm 0.04(.022)$ & \\
\hline Length of stay in ICU & & & $\mathrm{X}$ \\
\hline Total length of hospitalization & & $0.1 \pm 0.06(.044)$ & \\
\hline Delayed psychomotor development in childhood & $\mathrm{X}$ & & \\
\hline
\end{tabular}

and provide evidence that a substantial proportion of patients with TGA continue to display impaired global cognitive functioning in adulthood. IQ scores are important markers of cognitive function; however, they may not reflect the specific neuropsychologic individual strengths and weaknesses. Future assessments should examine specific cognitive domains (eg, attention, memory, executive functions) in adults with TGA to provide an in-depth developmental course for these abilities. This consideration is important for evaluation of the whole ACHD population because specific cognitive impairments are increasingly documented into adolescence $^{4}$ but remain rarely investigated in adulthood. ${ }^{3}$

Furthermore, in adults with TGA, cognitive difficulties were associated with lower HRQOL, lower educational level, and higher proportion of grade retention at school, highlighting the potential impact of such deficits on daily life functioning and academic achievement. This impediment to academic success could have, in turn, negative effects on socio-professional adaptive skills of these patients. In our study, the unemployment rate among nonstudent adults was slightly higher in patients $(23 \%)$ than in healthy subjects $(14 \%)$. Several studies reported lower educational levels ${ }^{18,19}$ and higher rates of unemployment in ACHDs. ${ }^{19,20}$ This increased risk deserves particular attention because education and employment are crucial factors of financial stability and well-being.

In patients and healthy subjects, we observed few cases of current depressive disorders $(0 \%-2 \%)$ but high frequencies of anxiety symptoms (35\%-39\%). The high prevalence of anxiety symptomatology in these young adults could be explained by the fact that early adulthood is a stressful period marked by changes and new challenges. During this period,
ACHDs may face additional difficulties (eg, scar-related discomfort, treatment decision-making, life-expectancy concerns) that could expose them to a greater risk.

Depression and anxiety are known to play an important role in quality of life and health outcomes. ${ }^{21}$ In our cohort, the presence of anxiety disorder was associated with poorer psychosocial HRQOL, suggesting that anxiety might have negative effects on social, academic, or occupational functioning of the patients concerned. Nevertheless, the relationship between anxiety disorder and HRQOL is not necessarily causal but may reflect the fact that these variables are influenced by common factors. Given their potential adverse effects and as mentioned in the guidelines for the care of ACHDs, ${ }^{2}$ psychologic disorders should be systematically screened in this population to provide appropriate treatment.

Similar to some findings in adolescents with TGA, ${ }^{22}$ our study showed that most adults with TGA reported HRQOL within or superior to normal ranges. Several hypotheses could explain these results. The use of normalization strategies (ie, coping strategies that enable individuals and families to maintain typical or "normal" life patterns despite the chronic illness) or a strong sense of coherence (ie, sense of confidence based on the understanding of life events, the feeling to be able to manage them, and that they have a meaning) seem frequently observed in this population $^{23,24}$ and could contribute to favorable outcomes. However, compared with healthy subjects, patients reported lower satisfaction in the physical HRQOL domain. This confirms previous data ${ }^{25}$ and highlights the need to develop therapeutic programs aimed at improving the quality of life, such as physical training and specific educational programs for particular challenges of ACHDs. ${ }^{26}$ 
With regard to risk factors associated with outcomes, we found that most surgical management variables we considered (including DHCA use or bypass and aortic clamp duration) were not associated with cognitive or psychologic scores. In children with CHD, surgical factors seem to be less relevant than patient-specific and preoperative factors and postoperative events in predicting neurodevelopmental outcomes. ${ }^{27}$ It is possible that the impact of intraoperative factors on outcomes may be even less manifest in adulthood, when 2 or 3 decades have passed since surgery. Longitudinal studies in adults may be necessary to confirm this. In our study, lower SEES was significantly associated with lower IQ. The influence of parental SEES on children's cognitive development is a well-known phenomenon ${ }^{28}$ also observed in patients with $\mathrm{CHD}^{27,29}$ In our cohort, older age at the ASO was significantly associated with lower IQ. The negative effect of older age at surgery on neurocognitive development is frequently observed in patients with $\mathrm{CHD}^{30}$ and could be interpreted by the fact that later correction of cyanotic CHD extends the period of hemodynamic instability during which the risk of hypoxia is high. ${ }^{31}$ In our study, predictors of higher anxiety symptomatology were variables related to the patients' care (older age at surgery, longer total length of hospitalization) that had already been identified as psychosocial predictors in children and adolescents with CHD. ${ }^{32}$ If later correction of cyanotic CHD could be associated with an increased risk of hypoxia, a longer length of hospitalization may be indicative of a less stable condition and more complications (hypotension, hypoxia, seizures) in the perioperative period. Surprisingly, we found that the presence of a VSD and the use of the Rashkind procedure before the ASO were associated with lower depressive symptomatology in adults with TGA. The presence of a VSD and the use of the Rashkind procedure both allow the mix of oxygenated and deoxygenated blood and therefore are generally associated with fewer risks of hemodynamic decompensation during the neonatal period. This, in turn, could have a favorable impact on specific long-term psychiatric outcomes. However, this remains speculative. These results should be interpreted with caution and deserve to be verified in larger groups to ascertain their clinical significance not only for the individual but also for the broader population with TGA.

\section{Study Limitations}

To our knowledge, this study is the first to address the cognitive outcomes of patients with TGA corrected by ASO during the crucial period of early adulthood. It provides evidence of substantial rates of cognitive and psychologic difficulties in the underinvestigated population of adults with complex CHD. However, the study should be interpreted in light of several limitations. Our study was cross-sectional and enrolled patients treated from the 1980s to the mid-1990s; thus, because of the rapid evolution of medico-surgical neonatal management over the last 20 years, our results might not be generalized to neonates born with TGA today. Moreover, to minimize confounders, we limited inclusion criteria to 1 cardiac defect (TGA with or without VSD) successfully repaired with a single open surgery (ASO) and excluded other cardiac anomalies and some potential risk factors of adverse neurocognitive outcome (eg, neurologic antecedents). Therefore, our results cannot be generalized to the larger population of ACHDs or to adults with TGA presenting such comorbidities. Although participants and nonparticipants were comparable in most clinical variables, patients included in our study had an earlier age at surgery, and those who underwent DHCA during the ASO had a shorter duration of arrest compared with the nonparticipant group. Furthermore, for an equivalent age, participants had a higher educational level than patients who refused to participate or accepted but never presented for evaluation. These differences support the fact that our cohort may represent a lower-risk part of the population of patients with TGA, with fewer cognitive difficulties and higher academic achievement. Indeed, given the known association between longer DHCA durations and lower cognitive outcomes, the fact that our cohort had significantly shorter mean durations of arrest (4 vs 30 minutes in the nonevaluated group) suggests that our findings may have underestimated the adverse impact of the TGA on outcomes. Thus, our results may not be generalized to patients with TGA with more complicated operative characteristics. In addition, because patients were evaluated at the hospital and healthy subjects were evaluated outside the hospital, the psychologist who administered tests was not blinded to participants' group status. However, tests were administrated and scored in accordance with a strict standardized procedure, reducing this potential bias. In our cohort, all patients were free of genetic syndrome diagnosis, as reported in medical records. Nevertheless, we did not conduct systematic genetic testing providing information on the patients' genotype and the presence of nonsyndromic genetic variations. There is growing evidence of the influence of nonsyndromic genetic variations, such as copy number variations, on the incidence of neurodevelopmental impairments in patients with CHD. ${ }^{33,34}$ Future research on the neurodevelopment of patients with CHD may integrate advanced genetic testing to better apprehend the potential impact of genetic polymorphisms on outcomes. Finally, because patients underwent operations in hospitals other than the recruitment institutions, some medical data serving as predictors of outcomes were missing. To conduct our regression analyses on the total cohort of patients $(\mathrm{n}=67)$ and improve prediction precision, ${ }^{35}$ we used the multiple imputations method. ${ }^{12,13}$ We carried out 5 
imputations to replace the missing data of variables having less than $25 \%$ of missing values. It is worth noting that our cut-point of $25 \%$ may be high and susceptible to some bias; thus, more conservative approaches for handling missing data could be considered. Results from our regression analyses should be interpreted with caution and verified in larger cohorts of adults with TGA.

\section{CONCLUSIONS}

Our results suggest that despite satisfactory cognitive or psychosocial outcomes in most adults with TGA corrected by ASO, a significant proportion presents substantial cognitive or psychologic difficulties that may reduce their quality of life and academic success. Further studies targeting more specific neurocognitive and psychosocial outcomes in adults with complex CHD are necessary to provide a more comprehensive approach in prevention, surveillance, and care of this population.

\section{Conflict of Interest Statement}

Authors have nothing to disclose with regard to commercial support.

The authors thank all of the participants for their kind participation and Eleonora Murzi for her help in the recruitment of healthy subjects.

\section{References}

1. Marino BS, Lipkin PH, Newburger JW, Peacock G, Gerdes M, Gaynor JW, et al. Neurodevelopmental outcomes in children with congenital heart disease: evaluation and management: a Scientific Statement from the American Heart Association. Circulation. 2012;126:1143-72.

2. Warnes CA, Williams RG, Bashore TM, Child JS, Connolly HM, Dearani JA, et al. ACC/AHA 2008 Guidelines for the Management of Adults With Congenital Heart Disease: A Report of the American College of Cardiology/American Heart Association Task Force on Practice Guidelines (Writing Committee to Develop Guidelines on the Management of Adults With Congenital Heart Disease) Developed in Collaboration With the American Society of Echocardiography, Heart Rhythm Society, International Society for Adult Congenital Heart Disease, Society for Cardiovascular Angiography and Interventions, and Society of Thoracic Surgeons. J Am Coll Cardiol. 2008;52:e143-263.

3. Tyagi M, Austin K, Stygall J, Deanfield J, Cullen S, Newman SP. What do we know about cognitive functioning in adult congenital heart disease? Cardiol Young. 2014;24:13-9.

4. Wilson WM, Smith-Parrish M, Marino BS, Kovacs AH. Neurodevelopmental and psychosocial outcomes across the congenital heart disease lifespan. Prog Pediatr Cardiol. 2015;39(2, Part B):113-8.

5. Grant JE, Potenza MN. Young Adult Mental Health. Oxford: Oxford University Press; 2010.

6. Wechsler D. Wechsler Adult Intelligence Scale - 3rd Edition (WAIS-3®). San Antonio, TX: Harcourt Assessment; 1997.

7. Zigmond AS, Snaith RP. The hospital anxiety and depression scale. Acta Psychiatr Scand. 1983;67:361-70.

8. Lépine JP, Godchau M, Brun P, Lempérière T. [Evaluation of anxiety and depression among patients hospitalized on an internal medicine service]. Ann Méd Psychol. 1985;143:175-89.

9. Ware JE Jr, Sherbourne CD. The MOS 36-item short-form health survey (SF-36). I. Conceptual framework and item selection. Med Care. 1992;30:473-83.

10. Leplège A, Ecosse E, Coste J, Pouchot J, Perneger T. Le Questionnaire MOS SF36: Manuel de l'utilisateur et Guide d'interprétation des Scores. Louvain-laNeuve: De Boeck Secundair; 2001.

11. Ware JE, Kosinski M. In: SF-36 ® Physical and Mental Health Summary Scales: A Manual for Users of Version 1. 2nd ed. Lincoln, RI: QualityMetric, Inc; 2001.
12. Rubin DB. Multiple Imputation for Nonresponse in Surveys. New York, NY: John Wiley; 1987.

13. Schafer JL. Analysis of Incomplete Multivariate Data. London: CRC Press; 1997.

14. Karsdorp PA, Everaerd W, Kindt M, Mulder BJM. Psychological and cognitive functioning in children and adolescents with congenital heart disease: a meta-analysis. J Pediatr Psychol. 2007;32:527-41.

15. Bellinger DC, Rivkin MJ, DeMaso D, Robertson RL, Stopp C, Dunbar-Masterson C, et al. Adolescents with tetralogy of Fallot: neuropsychological assessment and structural brain imaging. Cardiol Young. 2015;25:338-47.

16. Bellinger DC, Watson CG, Rivkin MJ, Robertson RL, Roberts AE, Stopp C, et al Neuropsychological status and structural brain imaging in adolescents with single ventricle who underwent the Fontan procedure. JAm Heart Assoc. 2015;4:e02302.

17. Heinrichs AKM, Holschen A, Krings T, Messmer BJ, Schnitker R, Minkenberg R, et al. Neurologic and psycho-intellectual outcome related to structural brain imaging in adolescents and young adults after neonatal arterial switch operation for transposition of the great arteries. J Thorac Cardiovasc Surg. 2014;148:2190-9.

18. Daliento L, Mapelli D, Russo G, Scarso P, Limongi F, Iannizzi P, et al. Health related quality of life in adults with repaired tetralogy of Fallot: psychosocia and cognitive outcomes. Heart. 2005;91:213-8.

19. van Rijen EHM, Utens EMWJ, Roos-Hesselink JW, Meijboom FJ, van Domburg RT, Roelandt JRTC, et al. Psychosocial functioning of the adult with congenital heart disease: a 20-33 years follow-up. Eur Heart J. 2003;24:673-83.

20. Crossland DS, Jackson SP, Lyall R, Burn J, O'Sullivan JJ. Employment and advice regarding careers for adults with congenital heart disease. Cardiol Young. 2005; 15:391-5.

21. Saarni SI, Suvisaari J, Sintonen H, Pirkola S, Koskinen S, Aromaa A, et al. Impact of psychiatric disorders on health-related quality of life: general population survey. Br J Psychiatry. 2007;190:326-32.

22. Culbert EL, Ashburn DA, Cullen-Dean G, Joseph JA, Williams WG, Blackstone E, et al. Quality of life of children after repair of transposition of the great arteries. Circulation. 2003;108:857-62.

23. Horner T, Liberthson R, Jellinek MS. Psychosocial profile of adults with complex congenital heart disease. Mayo Clin Proc. 2000;75:31-6.

24. Apers S, Luyckx K, Moons P. Quality of life in adult congenital heart disease: what do we already know and what do we still need to know? Curr Cardiol Rep. 2013;15:407.

25. Fteropoulli T, Stygall J, Cullen S, Deanfield J, Newman SP. Quality of life of adult congenital heart disease patients: a systematic review of the literature. Cardiol Young. 2013;23:473-85.

26. Ladouceur M, Iserin L, Cohen S, Legendre A, Boudjemline Y, Bonnet D. Key issues of daily life in adults with congenital heart disease. Arch Cardiovasc Dis. 2013;106:404-12.

27. Hövels-Gürich HH. Factors influencing neurodevelopment after cardiac surgery during infancy. Front Pediatr. 2016;4:137.

28. Bradley RH, Corwyn RF. Socioeconomic status and child development. Ann Rev Psychol. 2002;53:371-99.

29. Ballweg JA, Wernovsky G, Gaynor JW. Neurodevelopmental outcomes following congenital heart surgery. Pediatr Cardiol. 2007;28:126-33.

30. Miatton M, Wolf DD, François K, Thiery E, Vingerhoets G. Neurocognitive consequences of surgically corrected congenital heart defects: a review. Neuropsychol Rev. 2006;16:65-85.

31. Lim JM, Kingdom T, Saini B, Chau V, Post M, Blaser S, et al. Cerebral oxygen delivery is reduced in newborns with congenital heart disease. J Thorac Cardiovasc Surg. 2016;152:1095-103.

32. Latal B, Helfricht S, Fischer J, Bauersfeld U, Landolt M. Psychological adjustment and quality of life in children and adolescents following open-heart surgery for congenital heart disease: a systematic review. BMC Pediatr. 2009;9:6.

33. Gaynor JW, Wernovsky G, Jarvik GP, Bernbaum J, Gerdes M, Zackai E, et al Patient characteristics are important determinants of neurodevelopmental outcome at one year of age after neonatal and infant cardiac surgery. $J$ Thorac Cardiovasc Surg. 2007;133:1344-53.e3.

34. Homsy J, Zaidi S, Shen Y, Ware JS, Samocha KE, Karczewski KJ, et al. De novo mutations in congenital heart disease with neurodevelopmental and other congenital anomalies. Science. 2015;350:1262-6.

35. Lee KJ, Simpson JA. Introduction to multiple imputation for dealing with missing data. Respirol Carlton Vic. 2014;19:162-7.

Key Words: transposition of the great arteries, arterial switch operation, cognitive outcomes, health-related quality of life, early adulthood 